\title{
DEVOCIÓN MARIANA Y PODER REGIO: LAS VISITAS REALES AL MONASTERIO DE GUADALUPE DURANTE LOS SIGLOS XIV Y XV (CA. 1330-1472)*
}

\author{
POR \\ Francisco de Paula Cañas Gálvez \\ Profesor de Historia Medieval. Universidad Complutense de Madrid
}

\section{RESUMEN}

En este artículo se estudian las visitas regias a Santa María de Guadalupe durante los dos primeros siglos de su existencia, las causas de aquellos viajes y, sobre todo, sus consecuencias en la vida espiritual y económica del cenobio hasta convertirlo a mediados del siglo XV en uno de los centros políticos más activos de la Península Ibérica.

PALABRAS CLAVE: Corte real, monarquía castellana, patronato regio, devoción regia, Orden jerónima

\section{MARIAN DEVOTION AND ROYAL POWER: THE ROYAL VISITS TO THE GUADALUPE'S MONASTERY IN THE XIV AND XV CENTURYS (CA. 1330-1472)}

\begin{abstract}
In this article are studied the royal visits to the Monastery de Santa María de Guadalupe during the first two centuries of his existence, the reasons of those trips and, especially, his consequences in the spiritual and economic life of the
\end{abstract}

\footnotetext{
* Este trabajo se ha realizado en el marco del proyecto de investigación financiado por el Ministerio de Ciencia e Innovación $\mathrm{n}^{\circ}$ HAR2010-16762/HIST titulado «Prácticas de consenso y de pacto e instrumentos de representación en la cultura política castellana (siglos XIII al XV)». Investigador principal: Dr. José Manuel Nieto Soria.
} 
monastery up to turning it in the middle of the 15th century into one of the political centers from the Iberian Peninsula.

KEY WORDS: Royal court, castilian monarchy, royal patronage, royal devotion, hieronymite Order.

Recibido/Received 08-09-2011

Aceptado/Accepted 01-06-2012

Desde la fundación de su primer monasterio en el verano de 1374 en San Bartolomé de Lupiana por Pedro Fernández Pecha, el antiguo camarero mayor de Pedro I, la Orden Jerónima se situó muy pronto en una posición privilegiada en el entorno de la realeza castellana. Aquella pujanza espiritual habría de traducirse de manera rápida en una singular predilección de la Corona por sus monasterios como lugares de residencia y, por lo tanto, en auténticos centros de poder político desde donde se tomaron importes decisiones o tuvieron lugar acontecimientos de singular trascendencia histórica. Esta relación político-espiritual, sin duda ya muy bien consolidada a mediados del siglo XV en Castilla y de la que existen numerosos testimonios que iremos analizando a lo largo de este trabajo, culminó a mediados del siglo XVI con dos hechos de especial importancia para la Orden: la elección en 1557 del monasterio de Yuste como lugar de retiro y muerte del emperador Carlos $\mathrm{V}$, y, el que quizá sea su máximo ejemplo, la construcción del monasterio de San Lorenzo el Real de Escorial concebido por Felipe II como palacio y, por lo tanto, centro de gobierno de la Monarquía Hispánica, biblioteca y panteón de la Casa Real española. ${ }^{1}$

En todo el largo proceso que llevaría a la Orden al esplendor de los cenobios ya citados en el siglo XVI, el santuario de Santa María de Guadalupe jugó un papel destacado durante la Baja Edad Media, un papel que se acentuaría notablemente con la instauración de los Trastámara en el trono de Castilla, momento político, que en sus líneas generales, coincide, como ya hemos señalado, con el de la fundación de la Orden jerónima, y con la llegada de los primeros monjes al cenobio guadalupano.

Los orígenes de nuestro monasterio, al igual que ocurre con otras fundaciones de la Orden, son difusos y envueltos en la leyenda. ${ }^{2}$ Según ésta, en 1325 el

\footnotetext{
${ }^{1}$ Los orígenes de la Orden, su expansión por España y la protección recibida por parte de monarcas y nobles han sido temas tratados entre otros por Revuelta Somalo, J. M. 1982. Los jerónimos. Una orden religiosa nacida en Guadalajara: Guadalajara; Ruiz Hernando, J. A. 1997. Los Monasterios Jerónimos Españoles: Segovia. Sobre mecenazgo regio y nobiliario en la Orden Jerónima Ladero Quesada, M. A. 1986. «Mecenazgo real y nobiliario en monasterios españoles: los jerónimos (siglos XIV-XVI)». Príncipe de Viana anejo 3 47: 409-439.

2 Véase AHN, Códices, 48B y 101B. También Rubio, Fray G. 1926. Historia de Nuestra señora de Guadalupe, o sea: apuntes históricos sobre el origen, desarrollo y vicisitudes del Santuario y Santa Casa de Guadalupe: Barcelona; Sigüenza, Fray J. 1907-1909. Historia de la Orden de San Jerónimo: Madrid.
} 
pastor Gil Cordero encontró en las sierras cercanas la imagen de la Virgen que unos «clérigos santos» de Sevilla habían enterrado siglos atrás ante el avance musulmán en la Península Ibérica. ${ }^{3}$ La imagen, regalada por el Papa San Gregorio Magno a San Leandro de Sevilla, no se encontró, sin embargo, en un lugar casual, sino en una pequeña ermita que al parecer había sido construida para guardar los restos de San Fulgencio. ${ }^{4}$ Tras el descubrimiento, se levantó una nueva ermita de «piedra seca» y palos verdes cubierta de corcho que quedó al cuidado de Gil Pastor y su familia. 5

Gracias a algunos documentos expedidos por la Cancillería Real sabemos cómo era el aspecto que por entonces debía de tener esta antigua ermita. En diciembre de 1340 se afirmaba que era una «... casa muy pequeña, e estaba derribada...». Por entonces el lugar se había convertido ya en un centro muy concurrido de peregrinación mariana de tal manera que «... las gentes que y venian a la dicha ermita en romeria por deuoçion, no auian y do estar...». 6

De forma paralela a la creciente fama milagrosa del lugar, desde fecha muy temprana la Corona comenzó a dotar a la iglesia guadalupana de numerosas mercedes, encaminadas, la mayor parte de ellas, a afianzar su vida religiosa. En diciembre de 1337, por ejemplo, Alfonso XI ordenó a su vasallo Fernán Pérez de Monroy acotar términos para la iglesia de Guadalupe prohibiendo que pastasen en ellos los ganados no pertenecientes a los moradores de dicha iglesia, unos términos amplios y extensos que se habrían de extender a costa de los concejos de Talavera y Trujillo. ${ }^{7}$

Desde ese momento, las concesiones a la iglesia y el amparo que la realeza le había dispensado se intensificaron notablemente. En julio de 1340 Alfonso XI tomaba bajo su guarda la iglesia de Santa María de Guadalupe ${ }^{8}$ y unos meses más tarde, en diciembre, extendía carta de fundación presentando el priorazgo, patronazgo regio y dotación de la citada iglesia. Se ordenaba entonces que se construyeran casas para los clérigos que servían en la dicha iglesia y se concedieron terrenos para plantar viñas «... e labrança de pan para mantenimiento de los clerigos de la dicha yglesia... y de los clerigos e capellanes que y

3 Sobre los detalles del hallazgo véase AHN, Códices, 48B, fols. 6v-7r; y AHN, Códices, 101B, fol. VIv. También Pérez de Tudela y Velasco, Ma I. 1982. «Alfonso XI y el santuario de Santa María de Guadalupe». En la España Medieval (Ejemplar dedicado a la memoria de Salvador de Moxó, vol. II) 3: 271-274.

${ }^{4}$ AHN, Códices, 48V, fol. 5v.

5 Ibídem, fol. 8v.

${ }^{6}$ Así aparece mencionado en carta real de Alfonso XI fechada en Cadalso el 25 de diciembre de 1340. AHN, Clero, Carpeta 391, n 10, 11 y 12.

${ }^{7}$ Sevilla, 3 de diciembre de 1337. Confirmado en Salamanca el 26 de febrero de 1338 y en Illescas el 15 de abril de 1347. AHN, Clero, Carpeta 391, n 19.

${ }^{8}$ Sevilla, 16 de julio de 1340. AHN, Clero, Carpeta 391, nº 9. 
cantan en la dicha yglesia...». También se menciona la existencia de un hospital para pobres y un pequeño núcleo de población en torno a la ermita al que el rey le concedió tierras para que hiciesen sus casas y «... posiesen viñas e labranças de pan, e estos pobladores que diezmen el fruto de sus heredades e de sus labranzas a la dicha yglesia», ordenando, por último, el rey la construcción de una nueva iglesia en sustitución de la antigua, en mal estado, y presentando como prior perpetuo de ella al cardenal de España don Pedro Gómez Barroso, su antiguo proveedor. ${ }^{9}$ Las mercedes se vieron ampliadas por un privilegio de Alfonso XI de enero de 1342 que concedía la exención fiscal total para los ganados de la iglesia de Guadalupe que pastaran en Castilla, ${ }^{10}$ confirmada en sus líneas generales en $1347,{ }^{11}$ y por otro de agosto de 1348 por el que el rey permitía al arzobispo toledano Gil de Albornoz la presencia en el santuario de un prior, siendo nombrado entonces para el desempeño de tal cargo, y una vez fallecido el cardenal Gómez Barroso el año anterior, Toribio Fernández de Mena; ${ }^{12}$ la petición fue aprobada por el arzobispo unos meses más tarde, el 5 de octubre. ${ }^{13}$

LAS PRIMERAS VISITAS REgias a GuADALUPE: DE Alfonso XI A JuAN I (CA. 1330-1383)

A este desarrollo espiritual, institucional y económico auspiciado por la propia Corona castellana habría que añadirle desde principios de la década de 1330 el político al convertirse el primitivo santuario mariano en lugar cada vez más frecuentado por la realeza.

Aunque la primera visita documentada de un monarca, verificada en la persona de Alfonso XI, data del otoño de 1340, es posible, si atendemos a las palabras de fray Diego de Écija, que ésta tuviera lugar algunos años antes, en el transcurso de la década de 1330, cuando la fama de santidad de lugar comenzaba a extenderse por toda Castilla. Señala a este respecto el religioso jerónimo que «Como el noble rey don Alonso hubiese oído la mucha devoción que las gentes tenían en este santo lugar e iglesia de Guadalupe, donde está Nuestra Señora, que nuevamente había aparecido, y de los muchos y grandes milagros que esta Reina del Cielo tenía por bien de obrar en él con los que se le encomendaban y demandaban su ayuda a título de Guadalupe, movido con mucha devo-

\footnotetext{
${ }^{9}$ Cadalso, 25 de diciembre de 1340. AHN, Clero, Carpeta 391, n 10, 11 y 12.

10 Valladolid, 10 de enero de 1342. AHN, Clero, Carpeta 391, $\mathrm{n}^{\circ} 13$.

11 Illescas, 7 de abril de 1347. ANN, Clero, Carpeta 391, $\mathrm{n}^{\circ} 18$.

12 Santa María del Paular, 28 de agosto de 1348. AHN, Clero, Carpeta 392, no 2 y 7.

${ }^{13}$ AHN, Sigilografía, 59/5.
} 
ción de esta Madre de misericordia, propuso en su corazón de venir a visitar la santa imagen en esta su iglesia, de honrar y ennoblecer este santo lugar por ser visitado de ella». ${ }^{14}$

Quizá Écija se refiriera a la mencionada visita de finales de 1340, pero consultando los itinerarios seguidos por Alfonso XI durante aquellos años, podemos comprobar que el rey anduvo por tierras cacereñas en mayo de 1331, mayo de 1337 , enero de 1338 y mayo de $1339^{15}$ por lo que es posible, aunque la documentación no lo verifique, que el monarca visitara el santuario en cualquiera de estos viajes, o quizá en todos ellos, sobre todo teniendo en cuenta que además del fervor mariano del monarca habría que añadir la excelencia de la zona en aves de presa, en especial gavilanes, para la práctica de la cetrería a la que tan aficionado fue Alfonso XI como sus sucesores. ${ }^{16}$

Sea como fuera, y según apuntábamos más arriba, la primera visita regia documentada data de diciembre de 1340 y fue un acto político-religioso protagonizado por el propio Alfonso XI en agradecimiento a la intercesión de la Virgen María por la victoria cristiana en la batalla del Salado (30 de octubre de 1340). La crónica real narra así los motivos que llevaron al rey hasta el santuario: «E el rrey partido luego de Llerena e fue a Santa Maria de Guadalupe a dar graçias a Nuestra Señora, en quien este noble rrey don Alonso auie gran deboçion e a quien el se auie rrecomendado quando yva a pelar con los moros, e por la marauillosa vitoria que Dios, por rruego de su madre, le auia dado contra los rreyes Alboaçen, de Marruecos e de Benamarin e de Granada e offresçio muchas cosas; e mando que se escriuiese en su Coronica como Nuestra Señora auie aparesçido en aquel lugar al vaquero e se auia hallado alli soterrada su santa ymagen e se auia fundado e fecho alli auqella sacta yglesia de Guadalupe donde Nuestra Señora haze tantos milagros e de como el auia dado a aquella yglessia el termino que tenie de las tierras de Talauera e de Trugillo. E despues que dio loores el buen rrey a Dios e a Nuestra Señora de Guadalupe, partiose de alli e fuese su camino derecho para Madrid...».17

La peregrinación debió de influir notablemente en el ánimo del rey, de manera que, incluso, la Cancillería Real, dejó constancia escrita de aquella visita

${ }^{14}$ Écija, D. DE. 1953. Libro de la invención de esta Santa Imagen de Guadalupe; y de la erección y fundación de este Monasterio; y de algunas cosas particulares y vidas de algunos religiosos de él: 53 Cáceres.

15 Crónica del Rey Don Alfonso el Onceno. Edición de Cayetano Rosell, I, 1953: 228 (1331), 288 (1337) y 292 (1338) Madrid. La estancia de mayo de 1339 en RAH, Salazar, M-1, fol. 6r.

${ }_{16}$ Durante el reinado de Juan II el propio prior de Guadalupe era la persona encargada de proporcionar al monarca gavilanes para el ejercicio de este deporte. Vizuete Mendoza, J. C. 1988. Guadalupe: un monasterio jerónimo (1389-1450): 77 Madrid.

${ }^{17}$ Gran Crónica de Alfonso XI. Vol. II. 1976. Edición de Diego Catalán: 449 Madrid. 
en la mencionada carta de dotación y amparo regio a Guadalupe de diciembre de aquel año en estos términos: «E porque quando nos venimos de vençer al poderoso Albubazen, rey de Marruecos, e de Fez, e de Suzulmeza, e de Tremenén, e al rey de Granada en la batalla que ouiemos con ellos çerca de Tarifa, que fue lunes, veinte e nueue dias del mes de otubre de la era desta carta, venimos luego a este lugar por gran deuoçion que y ouiemos, ,..».18

Con posterioridad a esta romería, el rey volvió por tierras extremeñas en junio de $1344,{ }^{19}$ aunque como ocurría con las estancias reales por aquella zona durante la década de 1330 ninguna fuente evidencia la presencia del monarca en el santuario.

No volvemos a tener noticias de una visita real a Guadalupe hasta la realizada por Pedro I el 2 de septiembre de 1359, fecha en la que desde este lugar ordenó a los alcaldes, alguacil y hombres buenos de Talavera de la Reina respetar los privilegios que Alfonso XI y María de Portugal habían concedido a esta iglesia. ${ }^{20}$ Es posible que el rey hubiera podido pasar por el santuario durante sus visitas a Extremadura de marzo de 1351 y marzo de 1354, pero las fuentes documentales no nos permiten, una vez más, confirmar esta hipótesis. ${ }^{21}$

La política de Pedro I con respecto a Guadalupe fue, al igual que en el caso de su padre, de un sólido patronato a su iglesia ${ }^{22}$. Sabemos que en los primeros meses de su reinado confirmó, según era costumbre, todos los privilegios concedidos por su antecesor y no dudó en actuar decididamente a favor de Guadalupe cuando las circunstancias así lo requirieron. En julio de 1350, por ejemplo, recriminó duramente al obispo de Plasencia don Sancho por haber ido a la iglesia de Guadalupe a buscar al prior para asesinarle a pesar de tratarse de un lugar de patronato real, ordenándole, además, que devolviera todo lo que allí había robado; ${ }^{23} \mathrm{y}$ en noviembre de 1351 se puso a favor del prior cuando el arzobispo

${ }^{18}$ En realidad, la batalla del Salado tuvo lugar el lunes 30 de octubre y no el día 29 como afirma el propio monarca en la carta de privilegio. AHN, Clero, Carpeta 391, n ${ }^{\circ}$ 10-12. Recogido por Rodríguez Casillas, C. J. 2008. «Alfonso XI y Guadalupe: un punto y aparte en la historia de Extremadura», en XXXVI Coloquios Históricos de Extremadura: dedicados a la memoria de Inés de Suárez en el V centenario de su nacimiento (Trujillo, 24-30 de septiembre de 2007). Vol. 2: 640-641.

19 Barrios García, A. y Martín Expósito, A. 1986. Documentación medieval de los archivos municipales de Béjar y Candelario: Doc. 36, 86-88 Salamanca.

${ }^{20}$ Díaz Martín, L. V. 1975. Itinerario de Pedro I. Estudio y regesta: Doc. 745, 364 Valladolid.

21 Tanto el 9 de marzo de 1351 como el 11 de marzo de 1354 Pedro I se encontraba en la cercana villa de Medellín. En el primero de estos viajes el rey se dirigía desde Sevilla a Madrid por lo que es muy probable que en su trayecto a la actual capital de España se hubiera podido detener en Guadalupe. Ibídem, Docs. 67 y 598,164 y 316.

22 Díaz Martín, L. V. 1982. «La consolidación de Guadalupe bajo Pedro I». En la España Medieval 2: 315-336.

${ }^{23}$ Díaz Martín, L. V. 1975, Doc. 32,153. 
de Toledo Gonzalo de Aguilar le solicitó un servicio indebido de 500 maravedíes que había repartido entre los clérigos de Santa María de Guadalupe y a quienes excomulgó por no haberlos pagado. La decisión del rey fue firme y ordenó al prior que no abonase ningún servicio que le fuera reclamado. ${ }^{24}$

No conocemos ninguna estancia del sucesor de Pedro I, Enrique II, en Guadalupe, aunque sí consta que su esposa, Juana Manuel, ofreció al monasterio una capa de muy rico brocado, probablemente durante una posible romería. ${ }^{25}$ Sabemos, en cambio, que este monarca, el primero de la Casa de Trastámara, favoreció notablemente al santuario fundando doce capellanías dotadas con 12.000 maravedíes de moneda vieja situados en el almojarifazgo de Sevilla.. 26 También mostró el rey un singular interés por mejorar las condiciones de los viajes que los romeros hacían a Guadalupe y asegurarles una estancia confortable una vez llegados al santuario. En septiembre de 1375, por ejemplo, escribió al prior ordenándole que hiciera las reparaciones oportunas en los «palacios llamados del rey», en el término de Talavera de la Reina, para que se instalaran allí dos matrimonios encargados de su cuidado y dieran alojamiento y alimentos al propio rey, su corte y a los romeros cuando fuera necesario. ${ }^{27}$ Además de acondicionar los caminos para las visitas de los romeros, Enrique II puso un especial cuidado en la protección de los recaudadores de rentas de Guadalupe ${ }^{28}$ y dispuso que se pudieran celebrar ferias en La Puebla, diez días antes y diez después de la fiesta de Nuestra Señora de Guadalupe, y mercado los martes de cada semana sin tener que pagar por ello tributo alguno. ${ }^{29}$

Sí tenemos, por el contrario, noticias de, al menos dos viajes de Juan I al santuario; la primera el 22 de agosto de 1382, en el transcurso de un viaje que llevaba al rey desde tierras extremeñas, sede de sus tropas para la posterior entrada en Portugal, a Toledo; y la segunda, el 30 de abril de 1383, en una parada en su trayecto a Portugal donde se dirigía para recibir a la infanta Beatriz con quien contrajo matrimonio en Badajoz unos días después, el 21 de mayo ${ }^{30}$ Es muy posible que en esta visita a Guadalupe el rey estuviera acompañado del infante don Carlos de Navarra, por aquellos días con la corte de castellana camino de Badajoz. ${ }^{31}$

\footnotetext{
${ }^{24}$ Por carta de Pedro I fechada en Ciudad Rodrigo el 30 de noviembre de 1351. Ibídem, Doc. 409, 261.

25 Vizuete Mendoza, J. C. 1988: 294.

26 Ibídem 294.

27 Toro, 22 de septiembre de 1375. AHN, Sigilografía, 20/15.

${ }^{28}$ Burgos, 20 de noviembre de 1366. AHN, Clero, Carpeta 395, $\mathrm{n}^{\circ} 11$.

${ }^{29}$ Real sobre Toledo, 27 de junio de 1368. AHN, Clero, Carpeta 395, n ${ }^{\circ} 12$.

${ }^{30}$ Suárez Fernández, L. 1977. Historia del reinado de Juan I de Castilla. Tomo I. Estudio: 398-400 Madrid.

${ }^{31}$ Castro, J. R. 1967. Carlos III el Noble, rey de Navarra: 85 Pamplona.
} 
Aunque Juan I tan sólo visitó en dos ocasiones Guadalupe, es necesario resaltar que su reinado coincide con un proceso de extraordinario crecimiento económico e institucional de su iglesia auspiciado por la propia Corona y la decisiva labor del prior Juan Serrano, hombre cercano al rey y hábil político, convertido, por entonces, en obispo de Segovia. En agosto de 1389 Serrano visitó al rey en Sotosalbos, obteniendo del monarca el señorío de la Puebla de Guadalupe y la extinción del patronato regio. Previamente, Serrano había viajado a Lupiana donde consiguió que treinta y uno de los monjes allí residentes se trasladaran a Guadalupe para la fundación del nuevo cenobio. El 22 de octubre de ese año, «a la hora del Ángelus de la tarde», fray Fernando Yánez, acompañado de esos monjes, tomaba posesión de lugar y pasaba a ser el primer prior jerónimo de Guadalupe ${ }^{32}$ Con la conversión de Guadalupe en monasterio jerónimo, la nueva Orden y la propia Corona se ponían a la cabeza de la reforma religiosa española. ${ }^{33}$ La erección del monasterio fue confirmada más tarde por Benedicto XIII. ${ }^{34}$ Se iniciaba entonces una nueva etapa en las relaciones entre el nuevo monasterio extremeño y la monarquía castellana que habrían de culminar en la primera mitad del siglo XV como seguidamente pasaremos a estudiar.

LAS ROMERÍAS DE ENRIQUE III, JUAN II Y EL ENTERRAMIENTO DE MARÍA DE ARAGÓN: ESPLENDOR EN LAS RELACIONES DEL MONASTERIO CON LA REALEZA CASTELLANA

Durante los años del priorato de fray Fernando Yánez (1389-1412), en especial a partir de 1390, se acometieron importantes obras en el recién constituido monasterio. Se levantó entonces el claustro con sus dependencias, se avanzó en las obras realizadas en la iglesia y se construyó la capilla de San Martín o sala capitular. Cabe pensar si fue en aquellas fechas cuando se comenzaron a levantar los primitivos palacios reales que con una frecuencia cada vez mayor acogerían a los miembros de la Familia Real de Castilla en aquellas primeras décadas del siglo XV. ${ }^{35}$ En este contexto su construcción, desde luego, urgía, pues como romeros, tanto los propios miembros de la realeza como cualquier otro peregrino, gozaron desde finales del siglo XIV de numerosas indulgencias muy apetecibles que también fueron extensibles a todos aquellos que además ayudaran a la obra y sustento del monasterio u ofreciesen algo en las fiestas de Navidad y Ascensión de Nuestra Señora. ${ }^{36}$

\footnotetext{
32 Cañas Gálvez, F. DE P. 2007. El itinerario de la corte de Juan II de Castilla (1418-1454): 137138 Madrid.

33 Suárez Fernández, L. 1977: 351-372.

${ }^{34}$ Aviñón, 16 de febrero de 1395. AHN, Clero, Carp. 399, nº 2.

35 Cañas Gálvez, F. DE P. 2007: 138.

36 Vizuete Mendoza, J. C. 1988: 88-89.
} 
Si hasta entonces, el santuario había sido lugar de visitas más o menos esporádicas o circunstanciales de la realeza castellana, es a partir del reinado de Enrique III cuando el nuevo cenobio jerónimo, ya asentadas sus bases económicas y espirituales, se convierte en un importante centro político y religioso gracias, en parte, a las especiales relaciones mantenidas por algunos de sus priores con los miembros de la Corona, en especial con la reina María de Aragón. Ello no sólo se tradujo en la creciente influencia de algunos de sus priores en la corte, también, y de manera muy notable, en la concesión de un importante número de privilegios que vinieron a fortalecer, aún más, la solidez institucional de la nueva fundación. ${ }^{37}$

Como escenario de las luchas políticas en el seno de la corte de Castilla, Guadalupe adquiere entonces una relevancia notable. Gracias al trabajo de Nieto Soria conocemos los pormenores, con Guadalupe como escenario de fondo, de todo el proceso llevado a cabo tras la muerte de Juan Serrano, antiguo prior guadalupano y en el momento de su óbito obispo de Segovia, para esclarecer lo que bien parecía un asesinato por envenenamiento ante las pretensiones de Serrano y su contrincante, Gutierre Álvarez de Toledo, de ocupar la sede arzobispal toledana, vacante desde la muerte de Pedro Tenorio en 1399. ${ }^{38}$ Las irregularidades del proceso fueron, al parecer, numerosas y algunas de ellas, a los ojos de los propios contemporáneos de aquellos sucesos, abiertamente injustas contra varios inculpados que fueron torturados sin pruebas concluyentes siendo alguno de ellos trasladado a Guadalupe donde sufrió prisión humillante a cargo del alguacil del barrio de Santa María que «solía prender a los infames y las putas»..$^{9} \mathrm{Es}$, precisamente, en este complejo contexto político, en la primavera de 1402, cuando tiene lugar la romería de Enrique III a Guadalupe con Gutierre Álvarez de Toledo como principal encausado en el crimen, y preso, por ello, primero en Sevilla y más tarde, tras apelar ante la curia pontificia, en Guadalupe. La carta que el rey envió a su mariscal Diego Fernández desde la localidad sevillana de Constantina el 14 de abril de ese año de 1402 pone de manifiesto que la visita estaba proyectada con mucho tiempo de antelación. Aseguraba entonces el rey: «...por quanto yo tenja prometidas dos romerias, la vna a este monesterio de Sant Françisco (de Constantina) que yo fise, e la otra a Santa Maria de Guadalupe, de las quales yo non podia ser absuerto sin las con-

\footnotetext{
${ }^{37}$ El listado completo de los privilegios concedidos por Enrique III y Juan II a Guadalupe en Vizuete Mendoza, J. C. 1988: 53-83; y Cuadra, L. DE LA. 1973. Catálogo-inventario de los documentos del monasterio de Guadalupe: 47-112 Madrid.

${ }_{38}$ Nieto Soria, J. M. 2006. Un crimen en la corte: caída y ascenso de Gutierre Álvarez de Toledo, Señor de Alba (1376-1446): Madrid.

${ }^{39}$ Citado por Calderón Ortega, J. M. 2005. El ducado de Alba: la evolución política, el gobierno y la hacienda de un estado señorial (Siglos XIV-XVI): 44 Madrid.
} 
plir por my persona...».40 Enrique III llegó al monasterio a finales de ese mes de abril. El 29 consta ya su presencia dentro de los muros del cenobio, donde todavía permanecía el 5 de mayo. ${ }^{41}$

Dando por cerrada la pesquisa sobre la muerte de Juan Serrano, Enrique III atendió durante aquellos días en el monasterio diversos asuntos de trámite y autorizó al prior y a los vecinos de La Puebla de Guadalupe poder traer y meter pan, viandas, vino y otras cosas para el sostenimiento de los huéspedes y romeros que acudían al monasterio, la merced, no obstante, debió de confirmarse en años anteriores por su sistemático incumplimiento..$^{42}$ Después, el rey partió con dirección a San Martín de Valdeiglesias y posteriormente a Valladolid y Segovia. 43

No volvió Enrique III a Guadalupe. Si lo haría, en cambio, su hermano, el infante don Fernando, ferviente devoto mariano, al menos durante los días 10 y 11 de marzo de 1410, en una etapa del camino que le llevaba hasta la frontera de Granada, quizá para encomendarse a la Virgen en la preparación de la campaña militar que en septiembre de ese año acabaría exitosamente con la toma de Antequera. ${ }^{44} \mathrm{~A}$ principios del año siguiente, a su vuelta a la corte de Valladolid, el infante se detuvo de nuevo en Guadalupe, seguramente para agradecer a la Virgen el éxito militar obtenido. ${ }^{45}$

En los años posteriores no se conocen visitas reales al monasterio hasta enero de 1430, aunque no por ello el cenobio se mantuvo al margen de la intensa actividad política de la corte. Hacia 1417, por ejemplo, debió de tener lugar la entrega en custodia en el monasterio del rico tesoro, formado en su mayor parte por objetos de oro y plata de uso cotidiano en la cámara regia, que la reina Leonor de Alburquerque había traído de Aragón tras enviudar de Fernando I. ${ }^{46}$

Por aquellos mismos años, otros miembros de la realeza, la alta nobleza y el alto clero, no pocas veces durante el transcurso de alguna romería, otras mediante el envío por terceras personas, regalaron al monasterio importantes piezas litúrgicas, lo que, sin duda, ratifica el peso político-religioso que Guadalupe adquirió durante las tres primeras décadas del siglo XV. Sabemos que Fernando

\footnotetext{
${ }^{40}$ Carta misiva de Enrique III fechada en Constantina el 14 de abril (1402). AHN, Diversos, Colecciones, Leg. 287, s/f. Citado en Cañas Gálvez, F. DE P. 2007: 138.

41 Veas Arteseros, F. DE A. 2003: 417.

42 Por ejemplo, en 1421, 1422, 1434, 1435, 1438, 1439 y 1454. Vizuete Mendoza, J. C. 1988: 55 y 71.

43 Veas Arteseros, F. DE A. 2003. Itinerario de Enrique III: 417-420 Murcia.

${ }^{44}$ Cañas Gálvez, F. DE P. 2007: 138. La estancia el 10 de marzo en AM, Jerez de la Frontera, Actas Capitulares (1410, marzo, 20), fols. 44v-46r.

45 Crónica de Juan II de Castilla. 1982. Edición de Juan de Mata Carriazo: 413 Madrid.

46 Nieto Soria, J. M. 1997. «El tesoro de doña Leonor de Alburquerque, esposa de Fernando I de Aragón, en el monasterio de Guadalupe». Acta historia e archaeologica. Mediaevalia 18: 39-66.
} 
I de Portugal regaló una lámpara de plata y «otras limosnas», mientras que el infante Juan de Portugal, padre de Isabel de Avís, segunda esposa de Juan II de Castilla, obsequiaría con un cáliz de plata dorado y unas ampollas grandes de plata dorada «que se sacan cuando comulgan los frailes»; el infante Enrique de Aragón, un ornamento entero de terçiopelo; y el arzobispo de Toledo Pedro de Luna ofreció un cáliz de plata dorada que pesó siete marcos. Del mismo modo, décadas más tarde el infante Juan de Aragón, convertido ya en rey aragonés, enviaría una capa bordada con ruedas de oro. ${ }^{47}$

La referida ausencia de viajes al monasterio durante los años 1411-1429 no debe resultar extraña dadas las circunstancias políticas del momento. La minoría de edad del rey y los problemas derivados de los primeros enfrentamientos entre los infantes de Aragón y Álvaro de Luna, que tuvieron como escenario el centro peninsular, desaconsejaron cualquier viaje fuera de los puntos neurálgicos de la política castellana del momento. No sucedió, sin embargo, lo mismo con otros monasterios de la Orden localizados en aquel escenario político. La frecuencia de las visitas reales durante aquellos años a los cenobios de la Orden pone de manifiesto la predilección del monarca por los monasterios jerónimos a la hora de alojarse durante sus desplazamientos. Así ocurrió con el monasterio de Santa María de la Sisla, donde Juan II se hospedó en mayo de 1422 y al que volvería los días 27 y 28 de agosto de 1431 a su regreso de la campaña triunfal contra Granada. ${ }^{48}$ Otras estancias posteriores de este monarca en monasterios jerónimos se verifican en Nuestra Señora de Prado (15 de marzo de 1428 y 19 de mayo de 1429), Nuestra Señora de Fresdelval (12 de octubre de 1429), Santa María de la Mejorada (14 y 15 mayo de 1434 y 3 de julio de 1439), Montamarta (17 de febrero de 1442) y Nuestra Señora de la Armedilla (30 de octubre-2 de noviembre de 1444). 49

Volviendo a Guadalupe, de la mencionada estancia regia de mediados de enero de 1430 tenemos muy pocas noticias y tan sólo sabemos que el rey estuvo allí, al menos, los días 13 y 14 de enero a su regreso del castillo de Piedrabuena durante la campaña militar llevada a cabo por el rey contra los intereses de los infantes de Aragón en tierras extremeñas. ${ }^{50}$

Tras la firma de las treguas con los infantes de Aragón en el verano de 1430 en Almajano y su pérdida de influencia en los asuntos políticos castellanos a mediados de esa década, la vida política peninsular se tranquilizó notablemente. En este contexto de estabilidad, el año 1435 era el momento oportuno para realizar la romería que Juan II y su esposa deseaban hacer a Guadalupe. El Hal-

\footnotetext{
47 Vizuete Mendoza, J. C. 1988: 293-295.

48 Cañas Gálvez, F. DE P. 2007: 196 y 266.

${ }^{49}$ Ibídem 234, 242, 248, 289, 333, 359 y 386.

50 Ibídem 251.
} 
conero nos relató de manera muy pormenorizada los detalles del viaje. Juan II, acompañado del príncipe Enrique y el condestable Álvaro de Luna, partió de Madrid el 16 de febrero. Aquel mismo día llegaron a Móstoles para seguir días después por Casarrubios del Monte, Torre de Esteban Hambrán, Maqueda, villa del condestable en la que después de pedir permiso al rey partió con dirección a Toledo para ver el estado de las obras de la capilla que había ordenado construir en la catedral, más tarde Santa Olalla y, finalmente, Guadalupe donde la comitiva llegó, probablemente, el día $20.5^{51}$

La recepción que los monjes hicieron al rey a su llegada fue solemne. Una vez llegado el monarca ante las puertas del monasterio descendió de la mula en que viajaba y caminó junto a 30 caballeros con una rama verde en la mano. La entrada en el templo fue majestuosa. Allí le estaban esperando los 120 monjes que entonces profesaban en el cenobio para rezar en «...el altar de la Señora Santa María»; después el rey «... adoró la cruz...», retirándose más tarde a su cámara. Los días siguientes Juan II comió con los monjes en el refrectorio en compañía del príncipe Enrique y el prior fray Pedro de las Cabañuelas y visitó la granja de Santa Cecilia «...aquella casa tan hondrada e graçiosa...» donde le fue servida una comida por el prior, pudiendo, además, admirar los «...molinos de estanco, e ovo gran plazer en ver tan ondrado artifiçio; $\ldots . .^{52}$

La reina María, que había salido de Madrid el 18 de febrero, entró en Guadalupe el día 24 acompañada del arzobispo electo de Toledo, Juan de Cerezuela, hermano del condestable Álvaro de Luna. ${ }^{33} \mathrm{Si}$ bien es cierto, que la devoción de la reina por Santa María de Guadalupe era anterior a esta visita de 1435,54 también lo es que de aquella estancia en el cenobio nació una intensa relación espiritual y política entre la soberana y fray Pedro de las Cabañuelas, una relación que se materializó en su nombramiento como confesor de la reina y en una importante relación epistolar como evidencian las 130 cartas manuscritas de la reina encontradas en la celda de Cabañuelas tras su fallecimiento. La unión espiritual entre la soberana y el monasterio fue tal, que en su testamento doña María ordenó ser sepultada en Guadalupe, junto al altar mayor, a mano derecha conforme se entraba en la sacristía. El sepulcro debía ser de alabastro y su bulto en «forma y hábito de reina». Las exequias deberían ser las que se acostumbraban a hacer a las soberanas más las de todos los monjes di-

\footnotetext{
${ }^{51}$ Carrillo de Huete, P. 1946. Crónica del Halconero de Juan II, Edición de Juan de Mata Carriazo: 195-196 Madrid.

52 Ibídem 196.

53 Ibídem 195-196.

54 Ya en 1431 había concedido al monasterio 10.000 maravedíes de renta anual en la martiniega de la villa de Arévalo para dotar una capellanía por los reyes de Castilla, vivos y difuntos. Vizuete Mendoza, J. C. 1988: 79.
} 
funtos del monasterio. Determinó también doña María que los huesos de fray Hernando Yánez fuesen trasladados a su sepultura junto con los de quien había sido su confesor, fray Pedro de las Cabañuelas. ${ }^{55} \mathrm{El}$ monasterio fue el encargado de la construcción de la sepultura aunque ante la carencia de fondos para costearla el príncipe Enrique tuvo que librar 20.000 maravedíes en las carnicerías de Cáceres por espacio de 10 años. Además de la mencionada capellanía que la reina había dotado en 1431 con 10.000 maravedíes anuales, dispuso doña María en su testamento otras tres capellanías más en las que se habrían de celebrar cuatro misas semanales en cada una de ellas y un aniversario solemne en el que todo el convento descendería del coro para rezar un responsorio sobre su sepultura. Sin embargo, y a pesar de los esfuerzos del príncipe por cumplir las últimas voluntades de su madre, todo hace pensar que la dotación inicial de 20.000 maravedíes librada por don Enrique no fue suficiente para atender las capellanías dispuestas por la reina en su testamento, unas capellanías que para su correcto mantenimiento precisaban de cerca de 150.000 maravedíes. Con grandes esfuerzos hasta 1458 se mantuvo la capellanía con las dichas rentas de Arévalo, mientras que las otras tres ordenadas por la reina tuvieron serias dificultades para percibir anualmente los 20.000 maravedíes que en 1446 el príncipe Enrique les librara. ${ }^{56}$

Tras el fallecimiento de su esposa, Juan II volvió a Guadalupe en dos ocasiones más, una a finales de septiembre y la otra a finales de octubre de 1445, ida y vuelta de la campaña militar llevada a cabo contra los intereses de los infantes de Aragón en tierras extremeñas. Es muy posible que durante ambas estancias, el rey verificase personalmente las disposiciones testamentarias de su esposa en lo concerniente a su enterramiento en el monasterio. ${ }^{57}$

Aquellos años del reinado de Juan II también vieron la presencia de otros miembros de la realeza peninsular en Guadalupe. Sabemos que aprovechando su estancia en Castilla, donde había llegado en el verano de 1440 acompañando a su hija camino de Valladolid para desposarse con el príncipe Enrique, la reina Blanca de Navarra se trasladó a Guadalupe. Aunque no disponemos de muchos datos sobre este viaje, sabemos que debió de realizarse a finales de aquel año si tenemos en cuenta que la romería tuvo lugar tras la boda de los príncipes, el 15 de septiembre, y a mediados de enero de 1441 ya se encontraba de vuelta en Castilla. ${ }^{58}$ Fue probablemente durante esta romería cuando la reina donó al monasterio dos lámparas de plata. 59

\footnotetext{
55 Ibídem 79-80.

56 Idem.

57 Cañas Gálvez, F. DE P. 2007: 399-400.

${ }^{58}$ Ramírez Vaquero, E. 1999. «La reina Blanca y Navarra». Príncipe de Viana 60: 336.

59 Vizuete Mendoza, J. C. 1988: 293.
} 
Las visitas de Enrique IV, Alfonso V de Portugal y el Condestable MiGUEL LUCAS DE IRANZO: GUADALUPE Y LA DIPLOMACIA PENINSULAR

$\mathrm{Al}$ igual que su madre, Enrique IV sintió desde muy joven una devoción sincera y profunda por el monasterio de Guadalupe. Páginas atrás, vimos cómo en 1435, cuando tan sólo tenía 10 años de edad, acompañó a sus padres en romería al monasterio. El ambiente de profunda religiosidad del lugar y la cercanía de Cabañuelas a su madre (recordemos que era su confesor) y de fray Gonzalo de Illescas a su padre como consejero, debieron de influir notablemente en la temprana devoción guadalupana de don Enrique.

Desde su etapa como príncipe hay numerosos testimonios que ponen de manifiesto todo cuanto venimos afirmando. En enero de 1440, apenas cumplidos los 15 años, autorizó al prior y frailes del monasterio para que sus ganados pastasen en tierras de Trujillo permitiéndoles, además, cortar leña, madera y piedra en este lugar para trasladarla al monasterio. A ello habría que añadir los mencionados 20.000 maravedíes que en 1446 concedió para la dotación de las capellanías fundadas por su madre, la disposición dada en 1447 a los mayordomos, arrendadores y receptores de rentas del portazgo y montazgo de ciertas villas de la exención de pago que tenían los ganados de Guadalupe o la orden dictada en 1449 a las autoridades de Medellín para que no impidieran a los pastores del monasterio que sus rebaños pastasen en la sierra y monte de Rena. Ese mismo año de 1449, el príncipe otorgaba su carta de amparo y seguro para el monasterio y sus posesiones en tierras de Cáceres, Medellín y sus aldeas. ${ }^{60}$

$\mathrm{Al}$ año de llegar al trono, en 1455, y siguiendo la costumbre, Enrique IV confirmó al monasterio todos los privilegios concedidos por sus antecesores. ${ }^{61}$ Desde ese momento las mercedes se multiplicaron. Unos meses más tarde, en febrero de 1456, el rey autorizaba que se pidieran pedir limosnas por toda Castilla para acometer las obras que se estaban realizando en Guadalupe en consideración, según dice el propio rey, a ser el monasterio más notable del reino. ${ }^{62}$ Las visitas al monasterio no se retrasaron, registrándose la primera de ellas entre el 2 y 5 de marzo de 1456, en lo que fue una etapa de su viaje a Badajoz, ${ }^{63}$ y la segunda en abril de 1458. Sobre esta última estancia, la crónica de Miguel Lucas de Iranzo nos dice que el rey, siguiendo un itinerario similar al de su visita de 1456, «... partio de Madrid el dicho dia lunes de Quasimodo... y fue a la villa de Talavera.... y de allí fue a Guadalupe...».64

\footnotetext{
${ }^{60}$ Vizuete Mendoza, J. C. 1988: 82-83.

${ }^{61}$ Jaén, 2 de octubre de 1455. AHN, Sigilografía 3/27.

62 Talavera de la Reina, 18 de febrero de 1456. Ibídem 17/29.

${ }^{63}$ Véase RAH, Leg. 8/6.483 y AGS, QC, Leg. 1, fol. 296.

${ }^{64}$ Hechos del condestable don Miguel Lucas de Iranzo (Crónica del siglo XV). 1940. Edición de Juan de Mata Carriazo: 14. Madrid.
} 
Hasta su fallecimiento en diciembre de 1474, Enrique IV visitó en otras tres ocasiones más el monasterio de Guadalupe. Uno de estos viajes tuvo lugar entre, al menos, el 1 y el 8 de marzo de 1468 para pasar allí los carnavales. ${ }^{65}$ Ese mismo día 8, en el propio monasterio, el rey eximía de la jurisdicción de Trujillo todas las tierras y aguas de Santa María de Guadalupe. ${ }^{66}$ El siguiente fue a finales de 1469 y el último, que duró cuatro días, en febrero de 1472. ${ }^{67}$ Cabe dentro de lo posible que volviera en el verano de 1474 durante un viaje que realizó por tierras extremeñas, aunque la documentación conservada nos impide confirmarlo. ${ }^{68}$ Poco antes de morir, Enrique IV dispuso ser enterrado en el cenobio, en la capilla mayor «debaxo de la sepultura de la Reyna su madre Doña María». 69

Por aquellas fechas Guadalupe era ya un centro político destacado. No fue por ello extraño que recibiera la visita de monarcas extranjeros. Así ocurrió a mediados de mayo de 1464 cuando Alfonso V de Portugal decidiera marchar en romería al monasterio tras su campaña militar en Ceuta. Durante su estancia ofreció al monasterio una rica imagen de plata dorada del ángel, un portapaz de oro con piedras preciosas orientales y una rosa de oro que previamente le había enviado el Papa Martín V. ${ }^{70}$

Informado Enrique IV de la llegada del portugués al monasterio emprendió viaje para reunirse con él y celebrar un gran encuentro del más alto nivel político. Sin embargo, el monarca lusitano se adelantó hasta Puente del Arzobispo (Toledo) para ver a su hermana Juana, reina de Castilla, y a su sobrina, la infanta Isabel, «de hedat de treze años maravillosamente hermosa e no menos onesta e discreta», con quien Alfonso V pretendía contraer matrimonio. Contrariado por la negativa de Isabel que ante las intenciones del portugués, afirmó que la boda «... segun las leyes destos reynos esto no se podria ni devia hazer, syn consejo de los grandes del reyno...», regresó a Portugal y Enrique IV a Madrid. ${ }^{71}$

En este contexto de privanza regia guadalupana, pocos fueron los nobles que no advirtieron las posibilidades de promoción social y política que ofrecía mantener buenas relaciones con el monasterio y sus priores. Algunos acudieron

\footnotetext{
65 Torres Fontes, J. Sin año. Itinerario de Enrique IV: 212 Murcia.

${ }^{66}$ AHN, Clero, Leg. 1.422, $\mathrm{n}^{\circ} 66$.

67 Torres Fontes. Sin año: 229 y 250.

68 Ibídem 268-269.

${ }^{69}$ Citado por Domínguez Casas, R. 1993. Arte y etiqueta de los Reyes Católicos. Artistas, residencias, jardines y bosques: 350 Madrid.

70 Vizuete Mendoza, J. C. 1988: 294.

${ }^{71}$ Crónica anónima de Enrique IV de Castilla (1454-1474). 1991. Edición crítica y comentada de María Pilar Sánchez-Parra: 136 y 139 Madrid.
} 
en romería o para retirarse durante sus ejercicios espirituales y fundar capellanías, ${ }^{72}$ no pocos para morir, ${ }^{73}$ mientras que otros buscaron en la paz monástica el espacio idóneo para mediar en conflictos familiares ${ }^{74}$ y los más, como ya apuntábamos, para buscar favores, bien ante la propia Corona o los monjes cercanos a ella. Una forma eficaz de acercamiento era la donación de objetos litúrgicos de lujo y la concesión de mercedes y privilegios al monasterio. Entre la larga lista de magnates que de esta manera intentaron ganar afectos destacan Juan Pacheco, que entregó a los monjes doce cálices de plata dorados y otros doce pares de ampollas de plata, además de una corona de oro para la imagen de la Virgen; Juan de Guzmán, duque de Medina Sidonia y conde de Niebla, que ofreció una imagen de plata del parto de la Virgen y quince docenas de atunes de sus almadrabas; Pedro Girón, maestre de Calatrava, una capa rica de brocado azul y tres imágenes de plata doradas, una de la Virgen, otra de san Andrés y una última de san Antonio de Padua; Álvaro de Estúñiga, conde de Plasencia, un frontal rico de brocado morado y ornamentos de seda; o el condestable de Castilla Pedro Fernández de Velasco, que ofreció una lámpara de plata de ocho marcos con toda la renta perpetua para que ardiera siempre. ${ }^{75}$

Mención aparte merecen las figuras de Álvaro de Luna y el condestable Miguel Lucas de Iranzo. Del primero ya hemos tratado su romería junto a la familia real en 1435. Del segundo, cuenta su crónica que para su primer viaje a Guadalupe partió de Bailén el 5 de diciembre de 1459 acompañado de su esposa, María Teresa de Torres; Guiomar Carrillo, su madre; y Juana de Iranzo, su hermana. Antes de llegar comieron en la granja de Santa Cecilia, el mismo lugar donde lo había hecho Juan II en 1435, para entrar ese mismo día « $\ldots$ a dos oras de la noche, con muchas antorchas ençendidas». Una vez en el interior, el condestable descabalgó dentro de la iglesia mayor del monasterio. ${ }^{76}$

Durante su estancia en Guadalupe, Miguel Lucas permaneció retirado por completo de los negocios políticos. Después de haber cumplido con sus votos de devoción permaneció en el monasterio hasta la fiesta de Reyes Magos. Esos días, una vez pasados los rigores del retiro, estuvieron destinados a los «... plaçeres e faciendo muchas limosnas e dando muchas dáuidas a vnos y a

\footnotetext{
72 En 1430 Fernand Álvarez de Meneses había fundado una capellanía en el monasterio para la salvación de su alma. AHN, Nobleza, Frías, Leg. 1.281, nº 1 .

${ }^{73}$ Este podría ser el caso de Diego García de Orellana, III Señor de Orellana la Nueva, quien redactó y firmó en Guadalupe su testamento el 24 de febrero de 1471. RAH, Salazar, M-96, fols. 84r-96r.

${ }^{74}$ Hacia 1462 sabemos que Francisca Álvarez de Toledo, su hermano Fernán y Leonor de Estúniga habían firmado un compromiso por el que dejaban en manos del prior de Guadalupe el reparto de los bienes que quedaron por muerte de su padre, Fernán Álvarez de Toledo. AHN, Nobleza, Frías, Leg. $1.253, \mathrm{n}^{\circ} 27$.

75 Vizuete Mendoza, J. C. 1988: 295-296.

${ }^{76}$ Hechos. 1940: 31-32.
} 
otros», al monasterio le ofreció los ricos candeleros de plata que registran los libros contables del propio cenobio. ${ }^{77}$ Los asuntos políticos pronto recobraron su protagonismo habitual. Fue entonces cuando el condestable recibió en Guadalupe a un embajador del rey Carlos VII de Francia llamado mosén Juan de Fox «... el qual era vn muy gentil cauallero mançebo, de muy gentil presençia, y avía venido por enbaxador al rey nuestro señor... y así mismo avia traydo cartas al señor rey de Portugal y al señor Condestable, y por esta cabsa vino a Guadalupe». ${ }^{78}$

Las fiestas de recibimiento del embajador fueron magníficas. Se celebraron «... conbites y salas, y dançaron y baylaron; y el dicho cauallero dançó con la señora doña Juana, hermana del dicho señor Condestable, que era muy gentil dama y lo sabía bien facer». Después de varios días de celebraciones, Juan de Fox partió con destino a Sevilla y Córdoba no si antes prometer al condestable que a su vuelta de esas ciudades pasaría por Bailén donde don Miguel le esperaría en una de sus lujosas residencias. ${ }^{79}$

Un año más tarde, en los días previos a la Semana Santa de 1461, Miguel Lucas regresó de nuevo a Guadalupe y fue «... con muy grande onor e placer resçebido, como a señor a quien han muy singular amor». Después de varios días «... conpliendo sus votos e deuoçiones, e faciendo limosnas e sacrifiçios...» regresó a su exquisito y refinado palacio mudéjar de Jaén para las celebraciones del Jueves Santo. 80

Por último, para concluir este trabajo, señalar que no todos los nobles que visitaron Guadalupe lo hicieron por las razones antes dichas. El caso de Guiomar de Castro es, desde luego, significativo en este sentido y parece que su presencia en el monasterio en 1465 obedeció más a cuestiones de alcoba que a los aspectos señalados. Palencia, con su habitual agudeza, señala que ante las presiones de la reina Juana de Portugal, celosa de la privanza que doña Guiomar había alcanzado en la corte de Enrique IV, la dama había marchado a Guadalupe «... porque el rey, queriendo satisfacer a Beltrán y a la reina, la había alejado de su casa, aunque la veneraba mucho y deseaba verla casada con uno de los grandes». 81

\footnotetext{
77 Vizuete Mendoza, J. C. 1988: 296.

${ }^{78}$ Hechos. 1940: 32.

${ }^{79}$ Ibídem 33.

${ }^{80}$ Ibídem 63.

${ }^{81}$ Palencia, A. DE. 1999. Gesta hispaniensia ex annalibus suorum dierum collecta. Tomo 2. Libri VI-X: 300 Madrid.
} 


\section{CONCLUSIÓN}

Desde sus orígenes, el santuario de Santa María de Guadalupe atrajo el favor y la protección de la realeza y la alta nobleza de la Península Ibérica. Convertido en uno de los principales centros marianos de peregrinación de la Corona de Castilla, en 1389 tuvo lugar uno de los hechos trascendentales de su historia al pasar a ser monasterio de la Orden de San Jerónimo bajo los auspicios de la propia Casa Real.

Con una base económica sólida, una profunda espiritualidad y fama milagrosa que sobrepasaba las propias fronteras castellanas y un patronato regio cada vez más fuerte, Santa María de Guadalupe adquirió desde las primeras décadas del siglo XV el carácter de centro político y religioso que habría de caracterizarle aún durante buena parte de la Edad Moderna. Las visitas reales se hicieron entonces más frecuentes y algunos de los monjes pasaron a convertirse en consejeros o confesores reales ampliando, de esta manera, su poder político más allá del recinto monástico para extenderse a todos los dominios de la Corona. En este sentido, los reinados de Juan II y Enrique IV significaron el punto culminante de aquella relación entre la realeza y Guadalupe con ejemplos tan significativos como el de la reina María de Aragón, primera esposa de Juan II, quien movida por una devoción guadalupana firme y sincera ordenó su enterramiento allí, y lo mismo su hijo Enrique IV, que en su última voluntad dispuso que sus restos descansaran junto a los de su madre.

Consecuencia de todo ello, fue la dimensión que alcanzó durante aquellos años el monasterio como centro de cierto relieve diplomático. El encuentro de Juan II y su esposa con el condestable don Álvaro de Luna en 1435, la recepción de embajadores franceses en 1461 por el condestable Miguel Lucas de Iranzo o las proyectadas vistas entre Enrique IV de Castilla y Alfonso V de Portugal en 1465 tras sendas campañas militares en el Sur peninsular y el Norte de África respectivamente, vienen a confirmar esta teoría.

Cuando en diciembre de 1474 fallecía Enrique IV en Madrid, Santa María de Guadalupe era, sin duda, el centro espiritual más influyente en la Corona de Castilla y, junto con Madrid, Burgos, Segovia, Valladolid, Toledo o Sevilla, uno de los focos de poder más destacados de la Península Ibérica. Aquella proyección política aún habría de acentuarse más durante el reinado de los Reyes Católicos con la construcción de nuevos palacios por orden de la Reina Católica que deseaba pasar temporadas cada vez más largas dentro del monasterio. Era el principio de una nueva era en la historia de Guadalupe, una etapa marcada por el esplendor de la Orden y su proyección posterior en el Descubrimiento de América. 
FUENTES Y BIBLIOGRAFÍA

a. Archivos

Archivo General de Simancas (AGS):

- Quitaciones de Corte (QC)

Archivo Histórico Nacional (AHN):

- Clero

- Códices

- Diversos. Colecciones

- Sigilografía

Archivo Histórico Nacional (AHN). Sección Nobleza:

- Frías

Archivo Municipal de Jerez de la Frontera:

- Actas Capitulares. Año 1410.

Real Academia de la Historia (RAH):

- Legajos

- Salazar

\section{b. Bibliografía}

Barrios García, A. y Martín Expósito, A. 1986. Documentación medieval de los archivos municipales de Béjar y Candelario: Salamanca.

Calderón Ortega, J. M. 2005. El ducado de Alba: la evolución política, el gobierno y la hacienda de un estado señorial (Siglos XIV-XVI): Madrid.

Cañas Gálvez, F. de P. 2007. El itinerario de la corte de Juan II de Castilla (1418-1454): Madrid.

Carrillo de Huete, P. 1946. Crónica del Halconero de Juan II, Edición de Juan de Mata Carriazo: Madrid.

Castro, J. R. 1967. Carlos III el Noble, rey de Navarra: Pamplona.

Crónica anónima de Enrique IV de Castilla (1454-1474). 1991. Edición crítica y comentada de María Pilar Sánchez-Parra: Madrid.

Crónica de Juan II de Castilla. 1982. Edición de Juan de Mata Carriazo: Madrid.

Crónica del Rey Don Alfonso el Onceno. 1953. Edición de Cayetano Rosell, I: Madrid.

Cuadra, L. de La. 1973. Catálogo-inventario de los documentos del monasterio de Guadalupe: Madrid. 
Díaz Martín, L. V. 1975. Itinerario de Pedro I. Estudio y regesta: Valladolid.

Díaz Martín, L. V. 1982. «La consolidación de Guadalupe bajo Pedro I». En la España Medieval 2: 315-336.

Domínguez Casas, R. 1993. Arte y etiqueta de los Reyes Católicos. Artistas, residencias, jardines y bosques: Madrid.

Écija, D. DE. 1953. Libro de la invención de esta Santa Imagen de Guadalupe; y de la erección y fundación de este Monasterio; y de algunas cosas particulares y vidas de algunos religiosos de él: Cáceres.

Gran Crónica de Alfonso XI. Vol. II. 1976. Edición de Diego Catalán: Madrid.

Hechos del condestable don Miguel Lucas de Iranzo (Crónica del siglo XV). 1940. Edición de Juan de Mata Carriazo: Madrid.

Ladero Quesada, M. A. 1986. «Mecenazgo real y nobiliario en monasterios españoles: los jerónimos (siglos XIV-XVI)». Príncipe de Viana anejo 3 47: 409-439.

Nieto Soria, J. M. 1997. «El tesoro de doña Leonor de Alburquerque, esposa de Fernando I de Aragón, en el monasterio de Guadalupe». Acta historia e archaeologica. Mediaevalia 18: 39-66.

Nieto Soria, J. M. 2006. Un crimen en la corte: caída y ascenso de Gutierre Álvarez de Toledo, Señor de Alba (1376-1446): Madrid.

Palencia, A. DE. 1999. Gesta hispaniensia ex annalibus suorum dierum collecta. Tomo 2: Madrid.

Pérez de Tudela y Velasco, $M^{\mathrm{a}}$ I. 1982. «Alfonso XI y el santuario de Santa María de Guadalupe». En la España Medieval (Ejemplar dedicado a la memoria de Salvador de Moxó, vol. II) 3: 271-286.

Ramírez Vaquero, E. 1999. «La reina Blanca y Navarra». Príncipe de Viana 60: 323-340.

Revuelta Somalo, J. M. 1982. Los jerónimos. Una orden religiosa nacida en Guadalajara: Guadalajara.

Rodríguez Casillas, C. J. 2008. «Alfonso XI y Guadalupe: un punto y aparte en la historia de Extremadura», en XXXVI Coloquios Históricos de Extremadura: dedicados a la memoria de Inés de Suárez en el $V$ centenario de su nacimiento (Trujillo, 24-30 de septiembre de 2007). Vol. 2: 633-658.

Rubio, Fray G. 1926. Historia de Nuestra señora de Guadalupe, o sea: apuntes históricos sobre el origen, desarrollo y vicisitudes del Santuario y Santa Casa de Guadalupe: Barcelona.

Ruiz Hernando, J. A. 1997. Los Monasterios Jerónimos Españoles: Segovia. 
Sigüenza, Fray J. 1907-1909. Historia de la Orden de San Jerónimo: Madrid.

Suárez Fernández, L. 1977. Historia del reinado de Juan I de Castilla. Tomo I. Estudio: Madrid.

Torres Fontes, J. Sin año. Itinerario de Enrique IV: Murcia.

Veas Arteseros, F. DE A. 2003. Itinerario de Enrique III: Murcia.

Vizuete Mendoza, J. C. 1988. Guadalupe: un monasterio jerónimo (13891450): 77 Madrid. 